\title{
DA RACIONALIDADE ECONÔMICA À CONCEPÇÃO NORMATIVA DE RECONHECIMENTO: uma revisão teórica sobre perspectivas analíticas da ação coletiva e dos movimentos sociais
}

\author{
Glaucia F. O. Martins Batalha ${ }^{1}$
}

\begin{abstract}
RESUMO
O artigo pretende apresentar uma revisão teórica dos modelos analíticos da ação coletiva e dos movimentos sociais dos autores Mancur Olson, Eduard P. Thompson, Barrington Moore Jr., James Scott e Axel Honneth. Para concretização dos fins propostos, adota-se a metodologia que contempla o procedimento de pesquisa bibliográfica, uma vez que esta se volta para as diversas contribuições teóricas dos autores sobre a temática da ação coletiva.
\end{abstract}

Palavras-chave: movimentos sociais. ação coletiva. modelos analíticos. autores. contribuições teóricas.

\section{FROM ECONOMIC RATIONALITY TO THE NORMATIVE CONCEPTION OF RECOGNITION: a theoretical review on analytical perspectives of collective action and social movements}

\begin{abstract}
This paper intends to present a theoretical review of the analytical models of collective action and social movements of the authors Mancur Olson, Eduard P. Thompson, Barrington Moore Jr., James Scott and Axel Honneth. In order to achieve the proposed aims, the methodology that contemplates the bibliographic research procedure is adopted, since it focuses on the various theoretical contributions of the authors on the theme of collective action.
\end{abstract}

Keywords: social movements. collective action. analytical models. authors. theoretical contributions.

\section{Introdução}

A questão acerca de como e por que surgem as ações coletivas e os movimentos sociais tem sido norteadora para a construção das teorias sociológicas.

\footnotetext{
${ }^{1}$ Doutoranda em Ciências Sociais pelo Programa de Pós- graduação em Ciências Sociais da Universidade Federal do Maranhão - PPGCSOC/UFMA. Mestre em Direitos Humanos pelo Programa de Pós- graduação em Direito da Universidade de Federal do Pará- UFPA - PPGD/UFPA. Pós-graduada em Direito Administrativo e Administração Pública pela Universidade da Amazônia - UNAMA. Advogada pela OAB/MA. Professora e Coordenadora da Faculdade Santa Terezinha - CEST. Currículo Lattes: http://lattes.cnpq.br/1051668391621795. E-mail: gfomartinsbatalha@gmail.com . ID ORCID: https://orcid.org/0000-0002-0458-0319 .
} 
Em verdade, a teorização acerca das mobilizações coletivas é um foco de constante exame das Ciências Sociais - bem como da Sociologia e da Filosofia do Direito compreendendo uma multiplicidade de modelos analíticos e diferentes abordagens.

De maneira introdutória, pode-se afirmar que esse campo de estudo e análise não é unificado e destaca-se com uma vasta produção - nem sempre seguindo num mesmo sentido interpretativo - mesclando reflexões teóricas que ora privilegiam aspectos racionais ora enfatizam aspectos psicossociais ou emocionais, políticos ou culturais como fatores fundamentais para o engajamento e motivação coletiva.

Nessa esteira, o presente artigo tem por escopo apresentar as contribuições teóricoanalíticas de importantes autores em torno da temática da ação coletiva, além de discorrer sobre seus entendimentos acerca dos movimentos sociais.

Isto posto, tem-se como substrato e referencial teórico as perspectivas de cinco autores: Olson, Thompson, Barrigton Moore, Scott e Honneth. E é nesta lógica que pretendese edificar o objeto deste estudo com vistas a expor a chave explicativa de cada um destes autores, tais como: conceitos, categorias e abordagens.

Ressalta-se que, em que pese os autores selecionados se utilizem de alinhamentos teóricos e perspectivas diferentes, oferecem chaves analíticas relevantes para a compreensão do tema aqui proposto.

Frisa-se que que mobilização de diferentes concepções justifica-se por dois motivos principais. O primeiro refere-se ao ato de que pluralidade de interpretações acerca do fenômeno da mobilização coletiva permite explicar realidades específicas. O segundo é que a realidade dinâmica da sociedade e a heterogeneidade de objetos empíricos contextos exige reatualização de análises e aportes teóricos no decorrer do tempo, uma vez que "as mobilizações coletivas ganharam escala global, caráter violento e se concentram em bandeiras identitárias, compelindo teóricos a rever suas interpretações" (ALONSO, 2009, p.02).

Para concretização dos fins propostos, adota-se a metodologia que contempla o procedimento de pesquisa bibliográfica, uma vez que esta se volta para as diversas contribuições dos autores sobre a temática da ação coletiva. (BARDIN, 1977; CELLARD, 2012).

2. Os desdobramentos teórico-analíticos da ação coletiva e dos movimentos sociais 
Dos desdobramentos teórico-analíticos acerca dos estudos dos movimentos sociais, partimos da visão que encara a ação coletiva numa perspectiva puramente racional. Em sendo assim, apresenta-se a concepção de Mancur Olson em "A lógica da ação coletiva: os beneficios públicos e uma teoria dos grupos sociais" que enfatiza a utilização de modelos econômicos para a análise dos grupos sociais e da ação coletiva.

Para o autor o altruísmo é algo excepcional, haja vista que a ação é interessada de modo que os membros dos grupos "só" agem coletivamente quando há mecanismos incitativos para que os indivíduos se engajem. ( benefícios ou coerção).

Nessa lógica, a plausibilidade e a formação de grupos só será possível quando, e se, o retorno individual for superior ao investimento, uma vez que os indivíduos estão interessados em garantir, antes e mais nada, seu próprio benefício (seguindo a equação da maximização dos benefícios e minimização dos custos), sendo mister que o grupo lance mão de medidas que proporcione incentivos seletivos individualizados ( que não necessariamente sejam ou de coerções.

Portanto, os indivíduos racionais e centrados nos próprios interesses não agirão para promover seus interesses comuns ou grupais e nem formarão organizações para impulsionar seus objetivos, salvo se haja uma coerção ou bonificação que justifique e que transcenda os encargos comprometidos na obtenção dos propósitos grupais.

Ou como indica Olson, os membros de um grande grupo "não agirão para atingir seus objetivos comuns ou grupais a menos que haja alguma coerção para forçá-los a tanto, ou a menos que algum incentivo à parte (...) seja oferecido individualmente com a condição de que eles ajudem a arcar com os custos ou ônus envolvidos na consecução desses objetivos" (OLSON, 1999, p. 14-15).

Aqui percebe-se que a visão de ação coletiva de Mancur Olson se afasta da teoria tradicional dos grupos, donde a ação coletiva é fruto da participação voluntária de todos os membros do grupo com vistas a atender os interesses comuns (pressupondo uma nexo direto entre interesse individual e interesse grupal).

Nessa diapasão, Olson rebate a pressuposição vigente nas ciências sociais de que os grupos agem em interesse próprio porque os indivíduos assim o fazem. O que Olson enfatiza como um fator determinante de motivação para a ação individual é o resultado do cálculo racional entre benefícios e custos, afastando-se de explicações que tomem como norte emoções coletivas. 
Por esse ângulo, o que se destaca na concepção de Mancur Olson é o caráter individualista e racional que conduzem a ação coletiva de sorte que, ainda que haja elemento emocional ou ideológico "em jogo, tais recursos emocionais não são por si só suficientes para o financiamento de suas atividades básicas e vitais, sendo mister recorrer a contribuições compulsórias dos indivíduos.

As ações coletivas voltadas à satisfação dos interesses comuns acabam gerando benefícios públicos ou coletivos, definidos como qualquer benefício que, se desfrutado por um indivíduo, deve ser desfrutado por todos. Ou seja, há o problema do comportamento freerider (carona), pois aquele que não paga pelo benefício público, não pode ser impedido de desfrutar desse benefício (diferente dos benefícios não-coletivos que podem ser negado aos outros membros de um determinado grupo ou coletividade).

Do ponto de vista de Olson, a lógica de ação do indivíduo se baseará no sentido de adquirir mais benefícios individuais e arcar com o menor custo possível. Por tal razão, o indivíduo membro de um grande grupo tende a não participar da ação coletiva, uma vez que tem a ciência que seu esforço individual não tem um efeito notável sobre o grupo, de modo que poderá usufruir de quaisquer vantagens obtidas pelos outros envolvidos, quer tenha ou não arcado com os custos para a realização do benefício coletivo.

Isto posto, os grandes grupos que não puderem recorrer a contribuições compulsórias dos indivíduos, devem conceder benefícios não-coletivos/seletivos que leve os membros a agirem em prol de seus interesses comuns.

No que atine os grupos pequenos, estes são quanti e qualitativamente diversos dos grandes grupos. O argumento de Olson é que a interação face-a-face funciona como um mecanismo capaz de produzir o engajamento coletivo, uma vez que a pessoa tentará evitar a reprovação de seus conhecidos.

Em síntese, evidencia-se que para Mancur Olson o tamanho do grupo é um dos fatores determinantes para definir a busca racional e voluntária de um interesse individual gere comportamento grupal.

De todo o exposto, evidencia-se que Mancur Olson realiza a análise da ação coletiva que se afasta de explicações como pilares psicossociais e emoções coletivas atinentes a era clássica dos movimentos sociais. 
Segue numa perspectiva teórica que privilegia a racionalidade - reformando o padrão clássico da teoria dos movimentos sociais- donde a decisão de engajamento na ação coletiva é resultante da equação racional mais lucrativa entre custos e benefícios.

O próximo autor examinado é E. P. Thompson em "Costumes em Comum: estudos sobre a cultura popular tradicional". Ele é responsável por apresentar a "lógica da ação coletiva" numa outra perspectiva, para além de custos e benefícios individuais e da racionalidade econômica, perpassando pelo sentido de ilegitimidade e injustiça. Numa lógica de economia moral em consonância com o "código ético e moral popular" de um determinado contexto social e realidade histórica.

Ao estudar e analisar as rebeliões das multidões inglesas durante o século XVIII, Thompson se vale de fontes históricas para ressaltar aspectos costumeiros e culturais nos confrontos entre a nova economia política de "livre mercado" e a economia moral da plebe .

Aspectos de uma cultura popular que é rebelde, mas que o é em defesa dos costumes que visam legitimar seus protestos (THOMPSON, 1998, p. 19). Em outras palavras, a regulação nesse tipo de ordem social é tradicional e costumeira, baseada no paternalismo. Assim, evidencia-se a multidão se baseando nessas regras paternalistas, selecionando as que melhor defendam seus interesses presentes no sentido de resistir aos novos padrões de consumo, às inovações técnicas e à racionalização do trabalho.

Em seus escritos Thompson tece críticas a visão reducionista e espasmódica de historiadores no sentido de considerar, como linha de análise na rebeliões populares da Inglaterra do século XVIII, o elemento instintivo "fome" como legitimador da ação popular.

O autor se opõe a tal visão por entender ser um reducionismo econômico limitar a reação e os protestos da multidão como "rebeliões do estômago". Para Thompson, os aspectos sociais e culturais que devem ser considerados, um vez que os "motins da fome" se operavam por meio de uma noção legitimadora da ação popular, qual seja: a crença em estar "defendendo direitos ou costumes tradicionais" (Ibidem, p. 152).

Assim, diferentemente de uma reação espasmódica e fundada em necessidades alimentares, o "motim da fome" na Inglaterra do século XVIII era uma "ação popular direta, disciplinada e com objetivos claros" (Ibidem, p.152), que tinha como pressuposto referências morais e éticas da multidão - apontando como legítimas ou ilegítimas determinadas práticas em períodos de escassez- que constituíam a economia moral dos pobres. O desrespeito a tais 
referências e a visão tradicional das normas e obrigações sociais das funções econômicas tidas como legítimas gerava indignação e engajava a ação popular.

Ressalta-se que, no ensaio "Economia Moral Revistada”, E. P. Thompson rebate comentadores e críticos que apontam "objeções triviais" no trabalho do autor sobre economia moral da multidão inglesa, reafirma que o objeto de sua análise era a cultura política dos trabalhadores envolvidos em ações no mercado de um contexto específico e o seu método foi reconstruir o modelo paternalistas de mercado de alimentos e contrastar com a nova política “do mercado de grão" baseada na visão liberal de um mercado que autorregula, de acordo com as relação entre oferta e demanda.

Outrossim, foi demonstrar como em tempos de preços elevados e de penúria a multidão podia, por meio da ação direta, impor ao mercado um controle protetor e a regulação de preços, exigindo, por vezes, uma legitimidade decorrente do modelo paternalista.

Por tal razão, adverte Thompson que os resultados de "A economia moral" não podem ser transpostos para qualquer contexto e/ou realidades, mas para um ordem social de relações recíprocas.

Nessa lógica, os “motins' seriam uma resposta racional e um padrão sofisticado de um comportamento coletivo com fulcro numa "economia moral" daqueles grupos com pouco poder objetivando obstaculizar ações dos mais abastados e classes dominantes tidas como inaceitáveis e/ou ilegítimas pelo "código ético e moral popular".

Desta feita, o conceito de "economia moral" de Thompson, é uma ferramenta teórico-metodológica que conflui para a compreensão das ações coletivas e diretas de determinados contextos histórico-sociais, econômicos e políticos.

Fazendo uma intersecção entre Olson, Thompson e com o próximo autor explorado, qual seja, Barrington Moore Jr., pode-se asseverar que este se afasta da "racionalidade econômica" e da análise engendrada por Mancur Olson e se aproxima do sentido de "economia moral" de Thompson, mais especificamente no que atine às relações recíprocas entre grupos dominantes e dominados estabelecidas por um contrato social implícito.

Assim, em seu livro "Injustiça: as bases sociais da obediência e da revolta”, o autor traz uma questão central que norteia seu modelos teórico- analítico: "Por que as pessoas aceitam amiúde a condição de vítimas de suas sociedades enquanto, em outras ocasiões, ela se tornam tão iradas e buscam, com energia e paixão, fazer alguma coisa para mudar suas condições?" (MOORE JR., 1987, p. 9). 
Por esse ângulo, para Barrington Moore Jr. na base de toda autoridade, mesmo daquela mais primitiva, antes e acima de qualquer código legal, há um pacto implícito donde estão configurados direitos e deveres dos que mandam e dos que obedecem; um contrato em que estão estabelecidas as obrigações recíprocas dos dominantes e dos dominados. Ou seja, neste pacto estão previstos os princípios e os valores tidos como fundamentais e legítimos para governar aquela ordem social.

Portanto, pelo fato do contrato social implícito se edificar sobre a noção de legitimidade e reciprocidade (ou de justiça), no momento em que os deveres e as obrigações perante aos dominantes for inobservada (por negligência ou por descumprimento), há viabilidade para as revoltas e/ou ação coletiva se desenvolverem e transmudar a ordem social então vigente.

Em outros termos, o fracasso ou a recusa dos dominantes em realizar os encargos estabelecidos no contrato social implícito, além de representar a quebra dos princípios nele instituídos, desperta nos dominados o sentimento de injustiça, ponto de partida da desobediência e da revolta.

Além disso, o teórico aponta como motivador do fracasso da autoridade constituída as transformações nos princípios e nos sistemas de crenças até então correntes naquela ordem social. Isso se daria pois uma ou ambas as partes do contrato social implícito já não se reconhecem no que havia sido pactuado outrora, acarretando, assim, a necessidade do estabelecimento de novas regras sociais.

Todavia, no entendimento do teórico, para além de um contexto oportuno para a transmudação da realidade social opressiva ou injusta, há aspectos de cunho psicológicos e culturais que são "peças chaves" para a ocorrência de movimentos oposicionistas, uma vez que considera que as rebeliões ou ações coletivas não acontecem "sem mudanças na natureza humana, e as revoluções intelectuais não ultrapassam a condição de caprichos ou brincadeiras num contexto social desfavorável”(MOORE JR., 1987, p.126).

Nesse sentindo, o que o autor objetiva é "chamar atenção" para o processo de superação da autoridade moral que, de acordo com seus apontamentos, se dá por intermédio de três qualidades:

A primeira qualidade pode ser chamada de coragem moral, no sentido de uma capacidade de resistir a poderosas e ameaçadoras pressões sociais para a obediência a regras ou ordens 'opressivas' ou 'destrutivas'. A segunda qualidade é a capacidade intelectual para reconhecer que as regras e as pressões são de fato opressivas. (...). A 
terceira capacidade, a inventividade moral, é mais rara (...). É a capacidade de criar, a partir das tradições culturais vigentes, padrões historicamente novos de condenação ao que existe. (Ibidem, p.136-137)

Do exposto, entre outras conclusões do estudo empreendido por Barrington Moore Jr., evidencia-se como um norteador central a capacidade do indivíduo de ter a consciência e de reconhecer a opressão e a injustiça na ordem social, mas também de compreender que há certas condições desumanas, dolorosas ou degradantes das quais não se necessitam, não se podem e não se devem suportar.

Seguindo para a obra "A Dominação e a Arte da Resistência: discursos ocultos" de J.C. Scott e correlacionando com aspectos levantadas por E. P. Thompson, pode-se asseverar que diferente deste que estuda ações coletivas e diretas, o autor debruça-se sobre ações difusas e fragmentárias das formas cotidianas de resistência.

A tese central de Scott ergue-se no sentido de contestar a ideia de passividade e de ausência de resistência das camadas dominadas, apesar de lançadas cotidianamente em situações de subordinação, humilhação, opressão e violência.

Para J.Scott nem sempre a resistência e a insurgência de determinado grupos se dá por meio de ações extraordinárias e embates diretos e declarados publicamente, mormente em relações de poder desiguais.

Assim, o suporte teórico e as reflexões do autor traz à tona a presença da resistência clandestina- aquela que evita o confronto aberto e direto- nas camadas subalternas, por meio do discurso oculto e dos espaços sociais dissidentes, palco de micro-ações ordinárias e fragmentadas de resistências.

Isto é, Scott desvela uma categoria analítica que está por trás da arena e do discurso público, o que está para além das aparências, o que está "fora do raio" de audição e visão dos detentores de poder, qual seja: o discurso oculto ${ }^{2}$. O lugar sobreposto e privilegiando donde repousa e se estabelece a linguagem não-hegemônica e subversiva.

\footnotetext{
${ }^{2}$ O termo "discurso oculto" é usado por Scott para caracterizar o "discurso que tem lugar nos bastidores, fora do campo de observação direta dos detentores de poder” (SCOTT, 2013, p. 31), sendo produzido para um público específico e de modo que o dissenso e a revolta se desvelam apenas em pequenos círculos de confiança.

Via de regra, o discurso oculto contraria o discurso público de obediência passiva, e é anunciado em circunstâncias particulares, fora da cena pública e envoltas pela sensação de segurança/confiança em que os subalternos podem desabar sua raiva, criar fantasias de vingança, reagir contra as injustiças, violências e opressões.
} 
Para o teórico, em que pese, na maior parte do tempo, haja uma fachada de passividade e de aceitação da ordem do dominante por parte dos dominados, esta camuflagem da revolta perante tais relações tidas como injustas, coercitivas e depreciativas são estratégias de sobrevivência.

Os dominados tendem a moldar e dissimular seus comportamentos públicos- seja por cautela, medo ou interesse- às expectativas do detentores do poder. Essa transmissão de imagem exterior - com atos, gestos e expressões de deferência - está em conformidade com as normas das condutas defendidas de poderosos, como o autor identifica como discurso público ${ }^{3}$.

Outra categoria que Scott empenha-se em demonstrar é infrapolítica dos grupos oprimidos ( atos políticos que são disfarçados ou que estão fora da cena pública). Para o autor essa “a dimensão discreta da luta política” (SCOTT, 2013, p.235) é donde se assenta o sustentáculo social e normativo das formas práticas de resistência.

É o que proporciona os alicerces culturais e estruturais da ação política mais visível. Pois, em que pese, os grupos subalternos adotem comportamentos no sentido de não violar as normas e convenções sociais, estes são hábeis para construir estratégias e representar imagens de submissão e de passividade para tirar benefícios e/ou para preservar e proteger os espaços dissidentes e marginais das relações diretas de poder.

Diante da estratificação social que estabelece "os que mandam e os que obedecem", Scott apresenta repertórios - com atitudes e representações - que tem por objetivo transmitir, por parte dos dominados, uma imagem exterior de tolerância, subserviência e em conformidade com as condutas estabelecidas pelos detentores do poder, quais sejam: a deferência, a subordinação, a adulação, o controle do impulso e da raiva.

De acordo com o autor, a infrapolítica é uma forma elementar de política através do qual os grupos subordinados testarão os limites da dominação e questionarão frequentemente as fronteiras do permissível e, diante da diminuição ou enfraquecimento da vigilância e/ou das penalizações, podem se transmudar em insubordinações abertas e declaradas. Neste ponto de análise, é possível notar a estreita relação com as noções de obediência e reciprocidade estabelecidas por Barrington Moore Jr. em "Injustiça: as bases socais da obediência e da

\footnotetext{
${ }^{3} \mathrm{O}$ termo "discurso público" é usando pelo autor para designar as relações explícitas entre subordinados e detentores de poder. Importante notar que, o termo não se restringe ao disfarce, representação de deferência, lealdade e respeito dos subordinados para com os poderosos, mas também afigura-se uma ferramenta de interpretação adotada pelos grupos dominantes para produzir justificativas convincentes para a hegemonia de valores e do discurso dominante.
} 
revolta" no que tange "a sondagem entre governantes e súditos, a fim de descobrir e testa limites da obediência" (MOORE JR., 1987, p.39).

Scott considera a importância da compreensão da infrapolítica, dos seus disfarces, do seu desenvolvimento e da sua relação com o discurso público em face da concepção hegemônica que supõe a incorporação ideológica dos grupos subalternos a uma ordem dominante resultante de uma falsa consciência e da incapacidade de imaginar uma ordem social contrafactual.

Alicerçado nesses eixos, o autor critica a ideia de atribuir uma "falsa consciência" aos subordinados, pois assevera que as formas aparentes de aceitação perante quem exerce a dominação representam uma estratégia de resistência disfarçada.

Em verdade, Scott concentra seus esforços no sentido de problematizar e rebater as teorias da incorporação hegemônica e da falsa consciência, em particular as desenvolvidas a partir de Antonio Gramsci, de modo que, como resposta à sua posição subalterna na ordem social, criam estratégias de sobrevivência para lidar com o poder hegemônico, por meio do discurso oculto e da infrapolítica, e assim evitar o embater aberto e demonstrar a insubordinação.

Ao mergulhar na dinâmica da relação entre discurso oculto e a experiência da dominação e o mundo experimental da teoria reactância, Scott considera que por definição, o discurso público é anterior ao discurso oculto.

Por esse ângulo, autor ratifica que o discurso público compreende os seguintes domínios: a) domínio de apropriação material (ex.: de trabalhos, de impostos, de cereais) ; b) esfera de dominação e de subordinação pública (ex.: deferências, rituais de afirmação hierárquica, de punição, de humilhação,etc); c) domínio de justificação ideológica das desigualdades (mundividência política e religiosa).

No entanto ao promover a relação desta compreensão com o discurso oculto, Scott amplifica o campo de análise a fim de, não desconsiderar o domínio de apropriação material, mas privilegiar a experiência da submissão, deferência e humilhação como sementes da revolta. 
Para o autor as ofensas públicas à dignidade dos indivíduos e o não reconhecimento como pessoa representa um ponto crucial para surgimento do interesse em criar um espaço ${ }^{4}$ em que um discurso oculto coletivo de dignidade, de negação e injustiça possa ser elaborado com segurança.

Portanto, existência de espaços ${ }^{5}$ de maior autonomia dos grupos subordinados é primordial para a elaboração do discurso anti-hegemônico. O discurso oculto configura-se como sendo um espaço antecedente e preparatório para o desenvolvimento das manifestações, revoltas e confrontos públicos. E, a infrapolítica, uma ação primordial para romper a fronteira entre o discurso oculto e o público.

Do exposto, ratifica a importância do esforço teórico e analítico de Scott no sentido de oferecer para as Ciências Sociais e Jurídicas um aporte que permita diagnosticar condições propícias, tais como oportunidades políticas, que possam desencadear manifestações abertas e reivindicações na arena pública dos grupos subordinados. Mas, especialmente, por descortinar o discurso oculto, a infrapolítica e as formas cotidianas de resistência como chaves analíticas que, fogem aos grande momentos revolucionários, mas que são bases e sustentáculos valiosos para que estes momentos episódicos de explosão social venham a acontecer.

Afastando-se das categorias empreendidas por Scott relacionada à práticas cotidianas de resistência, parte-se para a concepção de Axel Honneth que busca "desenvolver os fundamentos de uma teoria social de teor normativo" (HONNETH, 2003, p. 23).

Ou seja, em sua obra central “Luta por Reconhecimento”, Honneth objetiva apresentar as dinâmicas práticas e cognitivas suscitadas pela vivência social negativa da escusa do reconhecimento.

Em vista disso, evidencia-se que os aportes epistemológicos de Honneth e seu desenho normativo do reconhecimento são chaves explicativas importantes para compreender a dinâmica da resistência social quanto à sua motivação, que se opera numa lógica dialética correlata da própria negação do reconhecimento.

\footnotetext{
${ }^{4}$ Ao estabelecer a necessidade do espaço social para o discurso oculto, Scott identifica tais espaços como lugares donde a dor à submissão e a raiva reprimidas podem ser reveladas, uma vez que, o controle, a vigilância e a repressão do poder não estão prementes e, portanto, mais difíceis de ocorrer.

${ }^{5}$ Frisa-se que Scott assevera que a noção de tais espaços sociais não se restringem a um local físico afastado, podendo ser esse lugar privilegiado e de uma sub-cultura dissidente, não apenas matagais, bosques, tabernas, hush arbors, lares, capelas, mercados, mas também lugares de sussurros, de olhares de códigos linguísticos e dialectos impenetráveis e indecifráveis pelos dominadores
} 
Para tanto o autor - que é um integrante expoente da tradição da Teoria Crítica ${ }^{6}$ remonta o conceito de reconhecimento do jovem Hegel do período de Jena, utilizando-o como fio condutor para compreender os conflitos sociais. Nesta toada, a luta política por reconhecimento estaria vinculada à experiência cotidiana dos sujeitos nas diversas esferas sociais.

Para Hegel o termo "reconhecimento" significa a relação ética entre dois sujeitos, donde no processo de formação da identidade surge a necessidade de reconhecimento recíproco (intersubjetividade). Desta feita, o indivíduo somente se vê como sujeito social a partir do reconhecimento pelos outros; quando for reconhecido pela comunidade que pertence. Se não houver este reconhecimento, não há portanto, a formação de um sujeito social e, então, esse indivíduo parte para o enfrentamento visando a busca pelo reconhecimento.

Além de Hegel, Mead e sua psicologia social também é referencial teórico de Honneth para atingir o fito de "traduzir a teoria hegeliana da intersubjetividade em uma linguagem teórica pós-metafísica" (HONNETH, 2003, p. 123), haja vista que, assim como Hegel, Mead parte da constituição do indivíduo através de relações intersubjetivas.

Nessa diapasão, Mead compatibiliza com Hegel a ideia de ampliação do reconhecimento jurídico como uma evolução moral da sociedade abrangendo dois processos, quais sejam: primeiro, o processo na qual todo membro da coletividade ganha em autonomia pessoal que "aumenta a dimensão do espaço para a liberdade individual"; segundo, o processo em que os direitos de uma coletividade "são transmitidos a um círculo cada vez maior de pessoas (...) a comunidade que se "amplia" no sentido social de que são incluídos nela número crescente de sujeitos pela adjudicação de pretensões jurídicas” (Ibidem, p. 146) .

Todavia, apreende-se das lições do autor que, assim como Hegel, há uma lacuna no modelo explicativo da "luta por reconhecimento" de Mead, pois

não se encontra uma consideração sistemática daquelas formas de desrespeito que podem tornar experienciável para os atores sociais, na qualidade de um equivalente

\footnotetext{
6 Honneth argumenta que a Primeira e Segunda Geração da Teoria Crítica sofreu de "Déficit Sociológico". egundo o autor, Habermas não conseguiu sociologicamente enraizar a visão que a Teoria Crítica tinha das formas de dominação e de possibilidades emancipatórias da política e da vida social. Assim, a noção de reconhecimento de Honneth é atrelado ao cotidiano dos sujeitos.
} 
negativo das correspondentes relações de reconhecimento, o fato do reconhecimento denegado" (Ibidem, p. 157).

Nesse sentido, resta evidente que Honneth busca um paradigma alternativo, orientado pelos modelos de Hegel e Mead, que comprove o nexo entre desrespeito moral e luta social. É com base nessa análise crítica que teórico vai propor uma concepção normativa de eticidade a partir de padrões de reconhecimento intersubjetivos: amor, direito e solidaridade.

Isto posto, pode-se afirmar que Honneth - ao atualizar o modelo hegeliano, bem como o meadiano- edifica sua teoria como sendo o reconhecimento uma expectativa recíproca de comportamento e ação que quando não efetivado desencadeia a dinâmica de conflito, qual seja a "luta por reconhecimento" o que acaba por ocasionar uma transformação social.

De outro modo, para o teórico o que possibilita a luta social é o fato das experiências negativas ultrapassarem o patamar de questões pessoais. São as vivências do desrespeito que suscitam a gramática do reconhecimento e podem se tornar a base para o surgimento dos movimentos sociais. Contudo, há uma condição para que o sentimento do desrespeito possa gerar uma mobilização social:

Tais sentimentos não podem, contudo, fornecer a base motivacional de uma resistência coletiva, se o sujeito não possua condições de formular um quadro de interpretação intersubjetivo desse desrespeito como típico de um grupo inteiro; nesse sentido, a emergência de movimentos sociais depende da existência de uma semântica coletiva que permite interpretar as experiências de desapontamento pessoal como algo que afeta não só o eu individual, mas também uma círculo de outros sujeitos"(HONNETH, 2003, p. 258).

Assim, quando a ausência do reconhecimento não é apenas de um indivíduo isolado, mas de uma grupo social, esta luta acaba por galgar contornos sociais e políticos, de maneira que o ponto central deste processo é o movimento em que o conflito e o reconhecimento condicionam-se mutuamente.

Por esse ângulo, Honneth tem como propósito demonstrar que a inserção de indivíduos e grupos sociais na sociedade se dá pelo reconhecimento (pela relação intersubjetiva) e não pela autoconservação para a preservação da identidade física como pressupõe as teorias contratualistas dos modelos hobbesiano e maquiavélico de luta social.

Todavia, o autor compreende que a luta por autoconservação é insuficiente para egendrar uma sociedade justa, pois "um contrato entre os homens não finda o estado precário 
de uma luta por sobrevivência de todos contra todos, mas, inversamente, a luta como um médium moral leva a uma etapa mais madura de relação ética"(Ibidem, p. 48).

É nessa análise crítica que Honneth vai propor uma concepção normativa de eticidade a partir de padrões de reconhecimento intersubjetivos: amor, direito e solidaridade. $\mathrm{O}$ amor gera a autoconfiança, o direito o autorespeito e a solidariedade a autoestima:

\begin{abstract}
O nexo existente entre a experiência de reconhecimento e a relação consigo próprio resulta da estrutura intersubjetiva da identidade pessoal: os indivíduos se constituem como pessoas unicamente porque, na perspectiva dos outros que assentem ou encorajam, aprendem a se referir a si mesmos como seres que cabem determinadas propriedades e capacidades. A extensão dessas propriedades e, por conseguinte, o grau da auto-realização positiva crescem com cada nova forma de reconhecimento, a qual o indivíduo pode se referir a si mesmo como sujeito: desse modo, está inscrita na experiência do amor a possibilidade da autoconfiança, na experiência do reconhecimento jurídico, a do autorespeito e, por fim, na experiência da solidariedade, a da autoestima (Ibidem, p.272)
\end{abstract}

Frisa-se que Axel Honneth pontua que a forma de reconhecimento do amor não contém experiências morais capazes de conduzir à formação de conflitos sociais, já que tais vivências não ultrapassam os limites das relações primárias.

Em contrapartida, as formas de reconhecimento do direito e da estima social, possuem uma estrutura moral própria dos conflitos sociais, já que dependem de critérios generalizáves, pois as experiências de desrespeito que um sujeito sofre podem afetar potencialmente outros indivíduos.

Desta feita, pode-se asseverar que a violação de qualquer um desses padrões de reconhecimento intersubjetivos motivam os indivíduos a procurarem novas relações éticas em que sejam reconhecidos, surgindo, então, a luta por reconhecimento a partir de uma ideia de gramática moral dos conflitos sociais.

No que tange o aspecto da auto-realização, o autor aponta que para a efetivação desta depende, além de liberdades negativas, de liberdades positivas que somente se experienciam através do reconhecimento.

Nesse sentido, a liberdade da auto-realização depende de pressupostos que não estão à disposição do próprio sujeito humano, visto que ele só pode adquirí-la com ajuda de seu parceiro de interação. Os diversos padrões de reconhecimento representam condições intersubjetivas que temos que pensar necessariamente quando queremos descrever as estruturas universais de uma vida bem sucedida". (HONNETH, 2003, p.273). 
Ressalta-se, ainda, que em sua obra Honneth utiliza os estudos de Barrington Moore Jr e E.P Thompson como suportes historiográficos para sua tese, pois, as mobilizações que esses autores analisam, a partir da ideia de economia moral, dialogam com a noção de luta pelo reconhecimento, além de substituir pressupostos utilitaristas por premissas normativas.

Ao promover essa interlocução com Barrington Moore Jr e E.P Thompson, Axel Honneth visar ampliar a concepção de tais autores, pois considera uma desvantagem nos estudos de ambos concederem um espaço pequeno ao "reconhecimento". Além disso, considera que ao se referirem as greves, revoltas ou resistências pacíficas de caráter meramente episódicos, não evidenciam a posição de desenvolvimento moral da sociedade:

(...) pois as lutas e conflitos históricos, sempre ímpares, só se desvelam sua posição na evolução social quando se torna apreensível a função que eles desempenham para o estabelecimento de um progresso moral na dimensão do reconhecimento. (Ibidem, p.265)

Do exposto, Honneth aponta para necessidade de conceber um modelo de conflito que não apenas explique o surgimento das lutas sociais, mas que também interprete seu processo de formação.

Para o teórico os sentimentos de injustiça e as experiências de desrespeito deixam de ser somente motivos da ação, mas passam a desempenhar um papel no desdobramento das relações de reconhecimento, sendo responsáveis pelo alargamento ou estreitamento do processo evolutivo da sociedade.

Em sendo assim, evidencia-se que a categoria "reconhecimento" honnethiana constitui-se, além de uma chave analítica, uma base argumentativa para um gama de movimentos sociais, pois para além de um reconhecimento jurídico, há uma fundamentação no reconhecimento social donde o elemento solidariedade é relevante para a composicão dos conflitos sociais. Ademais, o aprofundamento dessa temática pode constribuir para solucionar casos concretos de injustiça contra grupos vulneráveis.

\section{Considerações Finais}

A ação coletiva é um enigma. Nas Ciências Sociais, bem como na Sociologia e na Filosofia do Direito, há um vasto e diversificado campo teórico-analítico que envolve a ação 
coletiva e os movimentos sociais que buscam dar conta de esclarecer o que são, quais seus fundamentos, como se formam e quais características e categorias que lhe são particulares.

Explicações em torno do motivo pelo qual as pessoas se engajam em mobilizações coletivas, para além da ideia de condições materiais e recursos (racionalidade econômica), pode perpassar pela noção de economia moral, de quebra no contrato social implícito, de discursos ocultos ou de denegação de reconhecimento

Deste modo, o objetivo deste artigo foi justamente apresentar o esforço dos teóricos Mancur Olson, Eduard P. Thompson, Barrington Moore Jr., James Scott e Axel Honneth no sentido de deslindar questões, explicitar fundamentos, bem como apresentar categorias e traços que definem e compõe a ação coletiva e os movimentos sociais.

Optou-se por explorar os pensamentos e contribuições dos autores supracitados de modo a revelar que, em que pese se localizem em paradigmas diferentes, não se repelem mutuamente, podendo, em alguns aspectos se aproximarem, dialogarem e/ou interrelacionarem.

Em suma, ressalta-se que, além do enriquecimento de visão geral em torno da temática em foco, os desdobramentos teórico-analíticos aqui apresentados são caixas de ferramentas importantes para a realização de pesquisas sócio-jurídicas não apenas na órbita epistemológica mas também no campo empírico.

\section{REFERÊNCIAS}

ALONSO, Ângela. As teorias do movimento social: uma balanço do debate. Disponível em: ://www.scielo.br/pdf/ln/n76/n76a03.pdf. Acesso em: 09 ago. 2020.

BARDIN, Laurence. Análise de conteúdo. Lisboa: Edições 70, 1977.

CELLARD, A. A análise documental. In: POUPART, J. et al. A pesquisa qualitativa:

enfoques epistemológicos e metodológicos. Petrópolis, Rio de Janeiro: Vozes, p.295-316, 2012.

HONNETH, Axel. Luta por reconhecimento: a gramática moral dos conflitos sociais. Tradução de Luiz Repa. São Paulo: Ed.34, 2003.

MOORE Jr., Barrigton. Injustiça: as bases socais da obediência e da revolta. São Paulo: Brasiliense, 1987. 
OLSON, M. A lógica da ação coletiva: os benefícios públicos e uma teoria dos grupos sociais. São Paulo: Editora da Universidade de São Paulo, 1999.

SCOTT, James C. A Dominação e a Arte da Resistência: discursos ocultos. Tradução de Pedro Serras Pereira. Lisboa/Fortaleza: Letra Livre, 2013.

TARROW, Sidney. O poder em movimento: movimentos sociais e confronto político. Petrópolis: Vozes, 2009.

THOMPSON, E.P. A economia moral da multidão inglesa no século XVIII e Economia moral revisitada". Costumes em comum: estudos sobre a cultura popular tradicional. São Paulo: Companhia das Letras, 1998. 